\title{
Peran Organisasi Himpunan Mahasiswa Program Studi dalam Membentuk Karakter Kepemimpinan Calon Guru Kimia
}

\section{The Role of Organization Collage Student a Study Program to Build Leadership Character Candidate Chemistry Teacher}

\author{
Leony Sanga Lamsari Purba* dan Elisa Natalia Sibarani
}

FKIP Kimia, Universitas Kristen Indonesia, Jakarta-Indonesia

*Korespondensi: leony51@yahoo.com

\begin{abstract}
Abstrak: Perkembangan sosial media menjadi gaya hidup masa kini. Menurunnya keinginan anak untuk mengikuti komunitas-komunitas yang baik sebagai akibat penggunaan sosial media mempengaruhi pembentukan karakter dalam diri anak. Pendidikan karakter merupakan upaya yang sangat baik dari seluruh pihak yang turut membangun pendidikan. Pembekalan anak akan ilmu dengan karakter yang baik menjadi tanggung jawab seluruh kalangan yang terlibat dalam pendidikan demi masa depan yang bermartabat. Guru sebagai asset pendidikan harus memiliki visi yang baik bagi peningkatan pendidikan yang berkarakter. Organisasi merupakan suatu wadah bagi calon guru untuk membina watak. Penelitian ini bertujuan untuk mendeskripsikan peran organisasi mahasiswa program studi dalam membenuk karakter kepemimpinan calon tenaga pendidik Kimia Universitas Kristen Indonesia. Yang menjadi fokus dalam penelitian ini adalah Peranan organisasi himpunan mahasiswa program studi dalam membentuk karakter kepemimpinan calon tenaga pendidik. Dalam penelitian ini, pendekatan kualitatif dan rancangan penelitian studi kasus digunakan untuk mengumpulakn data dengan teknik (1) wawancara mendalam, (2) observasi nonpartisipan, (3) studi dokumentasi. Teknik analisis data menggunakan reduksi data, penyajian data, verifikasi atau kesimpulan. Hasil penelitian ini adalah Peranan organisasi himpunan mahasiswa program studi dalam membentuk karakter kepemimpinan calon tenaga pendidik dengan memberikan keberanian, integritas, rasa humor dan kedewasaan yang sangat baik, yakni masing-masing 96.5\%, 93,75\%, 93,75\%, dan 91,25\% pada calon tenaga pendidik. Jadi, mahasiswa diharapkan bergabung dalam organisasi himpunan mahasiswa program studi merupakan usaha yang di lakukan dalam membentuk karakter kepemimpinan calon tenaga pendidik Kimia Universitas Kristen Indonesia.
\end{abstract}

Kata kunci: karakter, pendidik, kimia

\begin{abstract}
The development of social media into today's style of life. The decline in the child's desire to follow communities a result of the use of social media affect the formation of character in children. Character education is a very good effort from all of people who develop education. Science briefing will children with good character is the responsibility of all of people involved in education for the future of dignity. Teachers is an asset in the world of education should have good prospects in education which is not a crisis of character. Organization is a place for prospective teachers to build character. This study aims to describe the role of student organization of study program in developing the leadership character of prospective educators of Chemistry Christian University of Indonesia. The focus in this research is the role of organization of student set of study program in shaping the leadership character of prospective educator. In this research, qualitative approach and case study research design is used to collect data by technique (1) in-depth interview, (2) nonparticipant observation, (3) documentation study. Data analysis techniques use data reduction, data presentation, verification or conclusion. The result of this research is the role of organization of student set of study program in shaping the leadership character of prospective educator by giving courage, integrity, good sense of humor and maturity which is 96.5\%, 93,75\%, 93,75\% and 91, 25\% on prospective educators. So, the students are expected to join the organization of student group of study program is effort done in shaping the leadership character of prospective educator of Chemistry Christian University of Indonesia.
\end{abstract}

Keywords: character, chemistry, educators

\section{PENDAHULUAN}

Perilaku Organisasi menurut Stephen $P$. Robbins (2006) adalah bidang studi yang mempelajari dampak perorangan, kelompok, dan struktur pada perilaku dalam organisasi dengan tujuan mengaplikasikan pengetahuan semacam itu untuk memperbaiki efektivitas organisasi. Perilaku organisasi adalah studi yang mengambil pandangan mikro memberi tekanan pada individu-individu dan kelompok-kelompok kecil. Perilaku organisasi memfokuskan diri kepada perilaku di dalam organisasi dan seperangkat prestasi dan variabel mengenai sikap yang sempit dari para pegawai, dan kepuasan kerja adalah yang banyak diperhatikan.

Topik-topik mengenai perilaku individu, yang secara khas dipelajari dalam perilaku organisasi adalah persepsi, nilai-nilai, pengetahuan, motivasi, serta kepribadian. 
Termasuk di dalam topik mengenai kelompok adalah peran, status kepemimpinan, komunikasi, dan konflik.

Secara garis besar ada tiga jenis pendekatan yang dilakukan oleh para ahli perilaku organisasi antara lain: (1) Pendekatan kognitif: Edward Tolman dalam Muhibbin Syah, (2009), berdasarkan pemahaman seseorang terhadap informasi. (2) Pendekatan behavioristic: I.P. Pavlov dan Anrep, G. V., (2003). berdasarkan respons yang muncul apabila diberi stimulus tertentu. (3) Pendekatan social learning: Albert Bandura (1986), berdasarkan pada penggabungan pendekatan kognitif dan behavioristic.

Keseluruhan garis besar pendekatan dalam organisasi dapat diajarkan melalui metode internalisasi untuk meningkatkan karakter seorang calon tenaga pendidik. Karakter kepemimpinan merupakan salah satu karakter yang dapat dilatih melalui berbagai cara, salah satunya adalah dengan mengikuti organisasi sekeliling oleh calon tenaga pendidik. Seiring waktu sangat memungkinkan karakter bertumbuh.

Menurut Majid dan Andayani (2012), pendidikan karakter adalah sebuah upaya untuk membimbing perila-ku manusia menuju standar-standar baku, pendidikan karakter adalah sebuah upaya untuk membimbing perilaku manusia menuju standar-standar baku.

Istilah karakter dimaknai sebagai "bawaan, hati, jiwa, kepribadian, budi pekerti, perilaku, personalitas, sifat, tabiat, temperamen, watak" (Depdiknas, 2010). Ciriciri karakter kepemimpinan sebagai salah satu jenis karakter yang harus dimiliki seorang calon tenaga pendidik secara umum menurut Fatchul Mu'in (2011) antara lain sebagai berikut: (1) Character is what you are when nobody is looking. (2) Character is the result of values and beliefs. (3) Character is a habit that becomes scond nature. (4) Character is not reputation or what other think about you. (5) Character is not how much better you are than other. (6) Character is not relative

Menurut John C.Maxwell (2010) ada 21 ciri pokok seorang pemimpin adalah: karakter; karisma; komitmen; komunikasi; kompetensi; keberanian; kepekaan; fokus; kemurahan hati; inisiatif; mendengar; semangat yang tinggi; sikap positif; memecahkan masalah; hubungan; tanggung jawab; kemapanan; disiplin diri; pelayanan; sikap mau belajar; impian.

Menurut US Army (dalam Danim, 2004) ciri-ciri karakter pemimpin yang baik adalah: dorongan, kemauan, keyakinan, empati, keberanian, keterusterangan, integritas, rasa humor, kompetensi, ketegasan, keadilan, komitmen, ketahanan, kreatifitas, kebijaksanaan, disiplin diri, inisiatif, kerendahan, kesejukan, fleksibilitas, kedewasaan dan peningkatan.

Thomas Lickona (2008) mengatakan seorang anak hanyalah wadah di mana seorang dewasa yang bertanggung jawab dapat diciptakan. Karenanya, mempersiapkan anak adalah sebuah strategi investasi manusia yang sangat tepat. Sebuah ungkapan terkenal mengungkapkan "Anak-anak berjumlah hanya sekitar 25\% dari total populasi, tapi menentukan 100\% dari masa depan". Sudah terbukti bahwa periode yang paling efektif untuk membentuk karakter anak adalah sebelum usia 10 tahun. Diharapkan pembentukan karakter pada periode ini akan memiliki dampak yang akan bertahan lama terhadap pembentukan moral anak.

Efek berkelanjutan (multilier effect) dari pembentukan karakter positif anak akan dapat terlihat, seperti yang digambarkan oleh J.L. Wallander (2005), "Kemampuan sosial dan emosi pada masa anak-anak akan mengurangi perilaku yang beresiko, seperti konsumsi alkohol yang merupakan salah satu penyebab utama masalah kesehatan sepanjang masa; perkembangan emosi dan sosial pada anak-anak juga dapat meningkatkan kesehatan manusia selama hidupnya, misalnya reaksi terhadap tekanan yang akan berdampak langsung pada proses penyakit; kemampuan emosi dan sosial yang tinggi pada orang dewasa yang memiliki penyakit dapat membantu meningkatkan perkembangan fisiknya."

Sangatlah wajar jika kita mengharapkan keluarga, sekolah dan lingkungan sebagai pelaku utama dalam mendidik dasar-dasar moral pada anak melalui proses pembelajaran formal maupun non formal. Menurut Miarso (2004) pembelajaran merupakan usaha mengelola lingkungan dengan sengaja agar seseorang membentuk diri secara positif tertentu dalam kondisi tertentu. Menurut Frankl dalam Bastaman (1996), bahwa setiap individu memiliki kapasitas untuk melawan lingkungan luas yang sulit, menahan dorongan fisik maupun psikologis untuk 
masuk ke dalam dimensi baru dari eksistensi diri. Dimensi baru ini adalah hal-hal mengenai meaning, dan meliputi dorongan untuk menjadi signifikan dan bernilai dalam kehidupan.

\section{METODE}

Penelitian ini dilakukan dengan menggunakan pendekatan kualitatif dan study kasus. Pendekatan kualitatif dan study kasus merupakan suatu proses penelitian dan pemahaman yang berdasarkan pada metodologi yang menyelidiki suatu fenomena sosial dan masalah manusia. Dalam mengumpulkan data, peneliti menggunakan kedua pendekatan diatas agar dapat mendeskripsikan pengaruh himpunan organisasi mahasiswa program study yang disingkat dengan HMPS terhadap perkembangan karakter mahasiswa sebagai calon tenaga pendidik. Menurut Blaxter et al. (2001), data itu dapat terdiri dari tanggapantanggapan terhadap sebuah kuesioner ataupun transkripsi-transkipsi wawancara, catatan-catatan atau rekaman-rekaman observasi serta dokumen dan data juga bisa terdiri dari yang bersifat numerik ataupun kata-kata. Agar dapat mendeskripsikannya, maka data akan dikumpulkan melalui empat cara.

\section{Wawancara mendalam}

Menurut Banister, dkk dalam Basuki (2006) wawancara adalah percakapan dan tanya jawab yang diarahkan untuk mencapai tujuan tertentu. Wawancara kualitatif dilakukan bila peneliti bermaksud untuk memperoleh informasi terkait perkembangan karakter dengan topik yang diteliti, dan bermaksud melakukan eksplorasi terhadap isu tersebut, suatu hal yang tidak dapat dilakukan melalui pendekatan lain. Sugiyono (2006) yang mengatakan bahwa dalam penelitian kualitatif, sering menggabungkan teknik observasi partisipatif dengan wawancara mendalam. Selama melakukan observasi, peneliti juga melakukan wawancara kepada orang-orang yang ada di dalamnya.

Dalam penelitian kualitatif dikenal teknik wawancara mendalam (Hariwijaya 2007). Teknik ini biasanya melekat erat dengan penelitian kualitatif. Wawancara mendalam (in-depth interview) adalah proses memperoleh keterangan untuk tujuan penelitian dengan cara tanya jawab sambil bertatap muka antara pewawancara dengan responden atau orang yang diwawancarai, dengan atau tanpa menggunakan pedoman (guide) wawancara di mana pewawancara dan informan terlibat dalam kehidupan sosial yang relatif lama.

\section{Observasi non partisipan}

Dimana observer tidak ikut di dalam kehidupan orang yang akan diobservasi, dan secara terpisah berkedudukan selaku pengamat. Di dalam hal ini observer hanya bertindak sebagai penonton saja tanpa harus ikut terjun langsung ke lapangan.

\section{Studi dokumentasi}

Menurut Djumhar dan Surya (1975) mengemukakan bahwa: tehnik memperlajari data yang mudah didokumentasikan disebut tehnik studi dokumenter. Adapun alasan menggunakan metode dokumenter adalah (a) dengan dokumenter data-data yang diperoleh secara utuh dan lengkap. (b) dengan dokumenter dapat menghemat waktu, biaya, tenaga walaupun data yang diperoleh cukup banyak.

\section{Angket}

Angket adalah suatu daftar atau kumpulan pertanyaan tertulis yang harus dijawab secara tertulis juga (W.S. Winkel, 1987). Angket disusun sebanyak 44 poin dengan bentuk pertanyaan positif dan diberi skor 1, 2, 3, 4, dan 5 dengan bentuk jawaban mengacu pada skala Likert dengan option sangat setuju, setuju, ragu-ragu, tidak setuju, dan sangat tidak setuju. Pernyataan dalam angket disusun dengan berpedoman pada ciriciri karakter kepemimpinan menurut US Army dalam Danim (2012).

\section{HASIL DAN PEMBAHASAN}

Fakultas Pendidikan dan Ilmu Pendidikan Universitas Kristen Indonesia terdiri atas delapan program studi FKIP UKI, satunya adalah Pendidikan Kimia. Sama halnya dengan prodi lain yang ada di FKIP UKI, program studi pendidikan kimia memiliki organisasi yang disebut HMPS (Himpunan Mahasiswa Program Studi). Organisasi tersebut dibina oleh salah seorang dosen pendidikan kimia, yaitu ibu Familia Novita Simanjuntak, M.Si. Organisasi ini dibentuk untuk mendukung visi dan misi program studi pendidikan kimia yang mengacu pada visi dan 
misi fakultas. Visi FKIP UKI yaitu menjadi fakultas unggulan dan inovatif di bidang ilmu pendidikan dan keguruan yang menghasilkan sarjana pendidikan berkualitas, adaptif dengan perkembangan IPTEK, berjiwa kepemimpinan, serta melayani berdasarkan nilai-nilai Kristiani. Melalui visi tersebut, diatas, peneliti mengumpulkan data mengenai jiwa kepemimpinan mahasiswa FKIP UKI secara khusus program studi pendidikan kimia. Aspek penilaian peneliti dibatasi pada fungsi organisasi program studi yakni HMPS dalam mendukung salah satu visi Fakultas Keguruan dan Ilmu Pendidikan di Universitas Kristen Indonesia.

Dalam mencari informasi, peneliti melakukan wawancara mendalam dengan dua jenis wawancara. Yang pertama, autoanamnesa (wawancara yang dilakukan dengan subjek atau responden), hasil yang diperoleh dari seluruh rangkaian pertanyaan yang di berikan kepada sepuluh orang mahasiswa yang dijadikan subjek penelitian, peneliti menyimpulkan bahwa setiap mahasiswa yang bergabung dalam HMPS merasakan perubahan dalam berkomunikasi dan menghadapi masalah. Yang kedua, loanamnesa (wawancara dengan teman responden), hasil yang diperoleh melalui beberapa pertanyaan yang dibeikan yaitu, menurut teman dekat mahasiswa yang menjadi subjek penelitian, mahasiswa subjek penelitian mengalami beberapa perubahan dalam bersikap, memimpin diskusi kelompok. Tidak berbeda jauh dengan hasil wawancara mendalam, hasil observasi non partisipan yang dilakukan oleh peneliti dengan memberikan lembar isian mengenai mahasiswa subjek penelitian kepada beberapa mahasiswa program studi pendidikan yang mengenal mahasiswa tersebut namun tidak satu kelas dan belum bergabung dengan HMPS.

Berdasarkan lembar isian tersebut, peneliti menyimpulkan bahwa secara umum, mahasiswa yang mengisi lembar observasi melihat ada beberapa perubahan sikap yang lebih baik pada mahasiswa subjek penelitian. Berdasarkan hasil skor observasi terlihat aspek sikap terbaik dari 20 orang yang mengisi lembar obsevasi, 80\% menyatakan perubahan pada berkomunikasi sangat baik.

Hasil data kualitatif yang ketiga diperoleh dengan cara studi dokumentasi. Beberapa dokumentasi yang diperoleh dari media sosial maupun secara langsung dari mahasiswa subjek penelitian, peneliti menganalisis beberapa dokumentasi. Dokumentasi pertama yaitu dari media sosial facebook, peneliti memperhatikan perkembangan update mahasiswa subjek penelitian, terlihat perkembangan pada hampir seluruh subjek penelitian. Perubahan yang terlihat jelas adalah pada foto dokumentasi maupun status mahasiswa mengenai kegiatan yang dilakukan di HMPS maupun diluar HMPS, mahasiswa mampu mengemukakan pendapat, mampu berdiskusi dan memimpin kegiatan. Dokumen kedua diperoleh dari foto-foto kegiatan yang ditempel dimajalah dinding program studi pendidikan kimia FKIP UKI. Berdasarkan analisis yang dilakukan terhadap dokumentasi yang diperoleh, peneliti memperhatikan terdapat beberapa perubahan dalam diri mahasiswa subjek penelitian secara umum. Menurut Young dalam Kartono (2006) pengertian kepemimpinan yaitu bentuk dominasi yang didasari atas kemampuan pribadi yang sanggup mendorong atau mengajak orang lain untuk berbuat sesuatu yang berdasarkan penerimaan kelompoknya, dan memiliki keahlian khusus yang tepat bagi situasi yang khusus.

Metode yang terakhir yang digunakan dalam mengumpulkan informasi terkait peran organisasi HMPS terhadap karakter kepemimpinan calon guru kimia adalah dengan menyebarkan angket kepada 20 orang mahasiswa program studi pendidikan kimia di UKI. Data yang di susun dalam excel di analisis kemudian disajikan dalam dalam bentuk diagram batang (Gambar 1).

Empat puluh empat poin angket yang disusun tersusun atas dua puluh dua ciri karakter kepemimpinan. Dari dua puluh dua ciri tersebut, terlihat dalam diagram hasil tabulasi angket yang disebarkan kepada dua puluh orang mahasiswa program studi pendidikan kimia UKI, bahwa rata-rata responden memilih option sangat setuju pada poin peningkatan keberanian, peningkatan rasa humor, peningkatan integritas dan kedewasaan. (Tabel 1).

Dari 20 orang responden, 17 responden sangat setuju terjadi peningkatan keberanian, 15 responden sangat setuju terjadi peningkatan keberanian dan rasa humor, dan 13 responden sangat setuju terjadi peningkatan kedewasaan pada mahasiswa calon guru kimia (Tabel 2). 


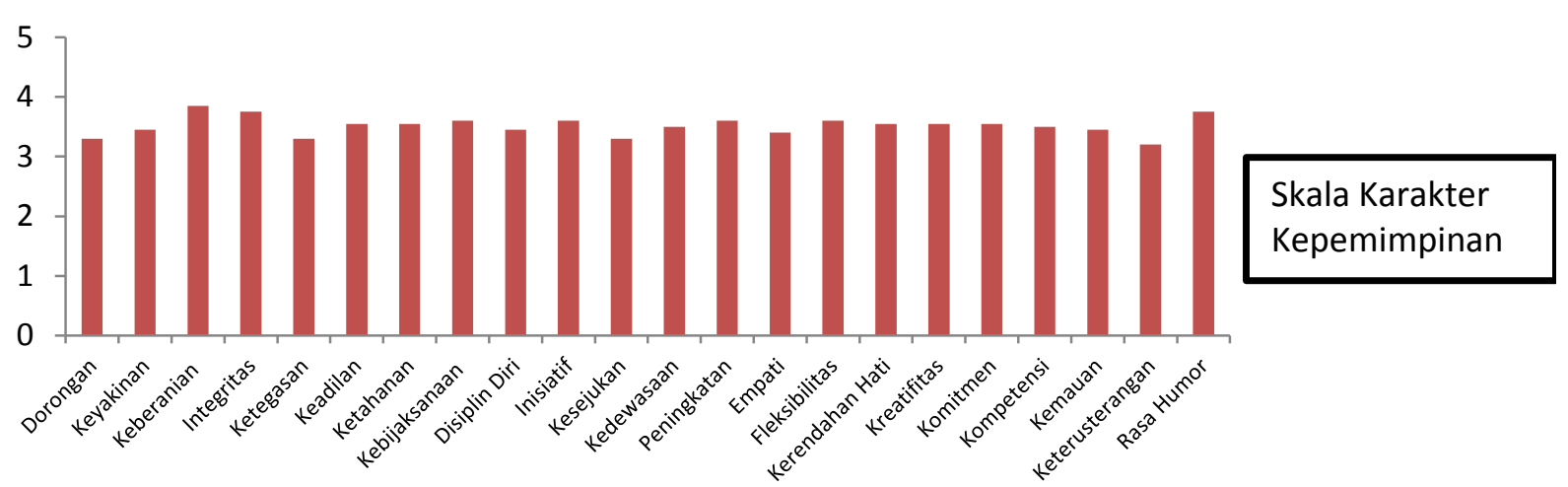

Gambar1. Tabulasi angket karakter kepemimpinan

Tabel 1. Persentase responden sangat setuju.

\begin{tabular}{lcc}
\hline $\begin{array}{c}\text { Karakter } \\
\text { kepemimpinan }\end{array}$ & Skala & $\begin{array}{c}\text { Persentase } \\
\text { responden sangat } \\
\text { setuju }\end{array}$ \\
\hline Keberanian & 3,85 & $96,25 \%$ \\
Integritas & 3,75 & $93,75 \%$ \\
Rasa Humor & 3,75 & $93,75 \%$ \\
Kedewasaan & 3,65 & $91,25 \%$ \\
\hline
\end{tabular}

Tabel 2. Persentase responden sangat setuju.

\begin{tabular}{lcc}
\hline $\begin{array}{c}\text { Karakter } \\
\text { kepemimpinan }\end{array}$ & Skala & $\begin{array}{c}\text { Persentase } \\
\text { responden } \\
\text { sangat setuju }\end{array}$ \\
\hline Komitmen & 3,5 & $87,50 \%$ \\
Kompetensi & 3,5 & $87,50 \%$ \\
Fleksibilitas & 3,5 & $87,50 \%$ \\
Inisiatif & 3,5 & $87,50 \%$ \\
Keadilan & 3,4 & $87,50 \%$ \\
Kebijaksanaan & 3,4 & $87,50 \%$ \\
Kemauan & 3,4 & $87,50 \%$ \\
Keyakinan & 3,4 & $87,50 \%$ \\
Ketahanan & 3,4 & $87,50 \%$ \\
Empati & 3,4 & $85,00 \%$ \\
Kerendahan hati & 3,4 & $85,00 \%$ \\
Kreatifitas & 3,4 & $85,00 \%$ \\
Didiplin diri & 3,35 & $83,75 \%$ \\
Kesejukan & 3,3 & $82,50 \%$ \\
Dorongan & 3,3 & $82,50 \%$ \\
Ketegasan & 3,3 & $82,5 \%$ \\
Keterusterangan & 3,2 & $80,00 \%$ \\
\hline
\end{tabular}

Untuk poin peningkatan yang lain ratarata responden memilih setuju. Dengan demikian, dapat disimpulkan bahwa mahasiswa mengalami peningkatan karakter kepemimpinan melalui organisasi himpunan mahasiswa program studi pendidikan kimia FKIP UKI.

Berdasarkan analisis peneliti terhadap hasil wawancara mendalam, observasi non partisipan dan studi dokumentasi serta penyebaran angket, terlihat bahwa HMPS program studi pendidikan berperan dalam membentuk karakter mahasiswa secara khusus dalam hal jiwa kepemimpinan mahasiswa. Dengan demikian, menurut peneliti HMPS berperan penting dalam pembentukan karakter kepemimpinan mahasiswa sebagai calon tenaga pendidik yang berkualitas sesuai dengan Visi dan Misi program studi yang juga mengacu pada fakultas FKIP UKI.

\section{KESIMPULAN}

Berdasarkan hasil dan pembahasan yang telah diuraikan diatas, peneliti menyimpulkan bahwa organisasi himpunan mahasiswa program studi (HMPS) pendidikan kimia berperan dalam mengembangkan karakter kepemimpinan mahasiswa sebagai calon tenaga pendidik. Dengan demikian, diharapkan kepada seluruh mahasiswa bergabung dengan organisasi himpunan mahasiswa program studi, agar jiwa kepemimpinan mahasiswa dapat dikembangkan.

\section{DAFTAR PUSTAKA}

Basuki, H.(2006). Penelitian Kualitatif untuk Ilmu-Ilmu Kemanusiaan dan Budaya. Jakarta: Gunadarma

Bastaman, H.D. (1996). "Meraih Hidup Bermakna". Jakarta: Paramadina

Basuki, S. (2010). Metode Penelitian. Jakarta: Penaku.

Blaxter, L.H., Christina, H., \& Thight, M. (2001). How to. Research (Seluk Beluk melakukan Riset) ed ke-2. Jakarta: PT. Indeks Kelompok Gramedia.

Danim, S. (2012). Menjadi Peneliti Kualitatif; Ancangan Metodologi, presentasi dan Publikasi Hasil Penelitian untuk Mahasiswa dan Peneliti Pemula Bidang 
Ilmu ilmu Sosial, Pendidikan dan humaniora. Bandung: Penerbit Pustaka

Danim, S. (2004). Motivasi Kepemimpinan dan Efektivitas Kelompok. Bengkulu : PT. Rineka Cipta.

Depdiknas. (2010). Panduan Pendidikan Karakter di SMP. Jakarta: Balitbang Depdiknas

Djumhar, I., \& Surya, M. (1975). Bimbingan dan Penyuluhan di Sekolah (Guidance \& Counseling). Bandung: CV Ilmu.

Hariwijaya, M. (2007). Metodologi dan Teknik Penulisan Skripsi, Tesis dan Disertasi. Yogyakarta: Elmatera Publishing.

Kartono. (2006). Pemimpin dan Kepemimpinan. Jakarta: PT. Rajagrafindo Persada

Lickona, T. (2008). Pendidikan Karakter, Panduan mendidik siswa menjadi pintar dan baik. Bandung: Nusa Media

Majid, A., \& Andayani, D. (2012). Pendidikan Karakter Perspektif Islam. Bandung: PT Remaja Rosdakarya.

Maxwell, J.C. (2010). 21 Ciri Pokok Seorang Pemimpin. Surabaya: PT Maju Insan Cemerlang
Miarso, Y. (2004). Menyemai Benih Teknologi Pendidikan. Jakarta: Pustekkom Diknas.

Mu'in, F. (2011). Pendidikan Karakter: Konstruksi Teoritik dan Praktik. Jakarta: Ar-Ruzz Media.

Pavlov, I.P., \& Anrep, G.V. (2003). Conditioned reflexes. Courier Corporation.

Robbins, S.P. (2006). Perilaku Organisasi (alih bahasa Drs. Benjamin Molan), Edisi Bahasa Indonesia, Klaten: PT INT AN SEJATI.

Sugiyono. (2006). Metode Penelitian Pendidikan, Pendekatan Kuantitatif, Kualitatif dan $R \& D$. Bandung: Penerbit Alfabeta

Syah, M. (2009). Psikologi Belajar. Jakarta: PT. Raja Grafindo Pustaka

Wallander, J.L. (2015). Dennis D. Drotar Distinguished Research Award: reflections on people and context influencing a research career. Journal of Pediatric Psychology, 40, 1001-1007. DOI: 10.1093/jpepsy/jsvo89

Winkel, W.S. (1987). Psikologi pendidikan dan evaluasi belajar. Jakarta: Gramedia Pustaka Utama. 